UDC: $316.722(=134.28)(497.11$ Pirot $)$

94(134.28)(497.11 Pirot)

DOI: https://doi.org/10.18485/hispserb.2019.2.ch27

\author{
Milena Vidosavljević ${ }^{1}$ \\ Doctoranda en la Universidad de Belgrado \\ Serbia
}

\title{
LA COMUNIDAD SEFARDÍ EN PIROT
}

\begin{abstract}
Resumen
Cuando la población sefardí fue expulsada de España en 1492 y Portugal en 1496, la vida de esta nación cambió completamente y se adaptó a nuevos entornos. Buscando el refugio en otros países, durante la dominación turca, los sefardíes llegaron a la ciudad de Pirot. En esta ciudad, los judíos españoles establecieron una comunidad judía y empezaron una nueva vida con la población local. Construyeron una sinagoga, el baño ritual - mikve, siguieron conservando las tradiciones y fiestas religiosas, pero al mismo tiempo se dedicaron con éxito a los trabajos de comercio. A pesar de pocos recursos materiales, los sefardíes en Pirot invirtieron en la educación de los jóvenes y otras actividades culturales y deportivas. Sin embargo, muchas guerras, empezando por la guerra serbobúlgara, pasando por las guerras de los Balcanes, la Primera Guerra Mundial y la Segunda Guerra Mundial provocaron situaciones desagradables y la desaparición de la comunidad sefardí de Pirot después del Holocausto, cuando muchos judíos fueron brutalmente torturados y asesinados en este suceso terrible.

Palabras clave: Los sefardíes, Pirot, la comunidad judía, la identidad étnica.
\end{abstract}

${ }^{1}$ mika_vido_88@yahoo.com 


\section{Introducción}

La expulsión violenta de España y Portugal en el siglo XV hizo que la población sefardí tuviera que encontrar un nuevo refugio, lo que les daría la oportunidad de construir su comunidad con el fin de preservar la identidad personal y colectiva, tradiciones, religión y costumbres. Al establecerse en otras ciudades, los sefardíes continuaron enfrentándose diariamente tanto con la población local como con las autoridades estatales y municipales.

El período de adaptación a nuevos lugares y personas tomó mucho tiempo, ya que sus migraciones se extendieron por diferentes países. Por lo tanto, los judíos españoles encontraron refugio en las ciudades de Serbia, incluida la ciudad de Pirot. Al llegar a esta ciudad, en la época del gobierno turco, un menor número de sefardíes fundó una comunidad judía que duró hasta los principios de la Segunda Guerra Mundial soportando muchas dificultades e inconvenientes causados por las guerras.

Aunque la comunidad judía de Pirot tenía solo 360 miembros, según el censo de 1879, logró cultivar sus costumbres y contribuir al desarrollo de la sociedad. Por lo tanto, el objetivo de este trabajo es mostrar la existencia y el funcionamiento de la comunidad sefardí y los sefardíes en Pirot, donde primero se representa su exilio, su llegada a Pirot y la organización de la sociedad, su vida religiosa, sus profesiones y su participación en las guerras. A continuación se destacan la importancia de la educación sefardí, de las actividades deportivas y otras influencias que tuvieron en la población local, y el evento implacable que extinguió la vida de muchos judíos, y por lo tanto causó un vacío doloroso y una gran tristeza en la ciudad de Pirot.

\section{El exilio de los sefardíes}

Los primeros testimonios documentados de la presencia judía, en el territorio de la Península Ibérica datan del siglo III a. C. Una comunidad judía muy significativa vivía en el territorio actual de España y Portugal, conocida como Sefarad. A partir de este territorio proviene "...el nombre de la rama de los judíos sefardíes de hoy (los sefarditas) que entre otras cosas tienen su propia lengua el ladino, una variante del castellano arcaico" (Soldatić \& Donić 2011: 80)². A pesar de que formaron buena parte de la población de la Península Ibérica, raramente se puede encontrar más

2 ,...ime grane današnjih Jevreja Sefarda (los sefarditas) koji između ostalog imaju svoj jezik el ladino, jednu varijantu ahraičnog kastiljanskog jezika“ (Soldatić \& Donić 2011: 80). 
información en los documentos sobre la llamada España judía, junto a la famosa España cristiana y morisca, ya que este país era conocido entre los historiadores. Lo que sí es conocido es que vivían hasta finales del siglo XV en diferentes partes de España como Toledo, Córdoba, Sevilla, Palma de Mallorca y Girona (Soldatić \& Donić 2011: 80).

Muchas circunstancias sociales, como la Inquisición, tuvieron una gran influencia sobre los judíos españoles porque las circunstancias del siglo XV eran desfavorables para sus vidas en este país. Aunque la amistad con los judíos trajo beneficios económicos a los reyes de ese período, el proceso de expulsión comenzó a partir de la llegada de Isabel I de Castilla, que estaba bajo la fuerte influencia de la iglesia. Durante ese período, su esposo Fernando de Aragón, ocupado en la liberación de Granada, suspendió la decisión de expulsar a los sefardíes. Sin embargo, después de la caída de Granada, los Reyes Católicos proclamaron un decreto de expulsión definitiva de los judíos con una prohibición explícita de exportación de dinero y metales preciosos (Soldatić \& Donić 2011: 84). En 1492 comenzó la expulsión de judíos que rechazaron cambiar de religión y pasar al catolicismo. Alrededor de 100.000 de ellos abandonaron España en ese momento y comenzaron a establecer comunidades sefardíes en otros territorios (Baho Alvares \& Hil Pećaroman 2003: 103).

Desde ese momento, la vida y el destino de los sefardíes fueron cambiando a lo largo de los años. Después de la persecución, la población sefardí comenzó a asentarse en el Mediterráneo: en el sur de Francia, en los países del norte de África, Italia, el Imperio Otomano y los Países Bajos. Una gran parte de los judíos sefarditas se desplazó hacia el este y gracias al sultán Bayaceto II (1481-1512) se instaló en Estambul, Salónica y ciudades de Asia Menor (Vučina Simović \& Filipović 2009: 41). El flujo de su asentamiento continuó en otras áreas, por lo que incluso durante el reinado de Solimán el Magnífico (1520-1566) llegó a los Balcanes, primero a Macedonia, y más tarde a Bulgaria, Serbia, Rumania y Bosnia (Vidaković Petrov 2001: 10-14, Nezirović 1992: 17-20, Hassán 1995: 118-120 apud Vučina Simović \& Filipović 2009: 41).

Muchos judíos españoles se establecieron en Sarajevo, Belgrado, Bitola, Skopje y en menor número en otras ciudades del sur de Serbia (Stanojević 1926: 131). Una vez encontraron refugio en estas ciudades, comenzaron a desarrollar su vida en la ciudad de Pirot. A diferencia de otras ciudades de Serbia, donde las comunidades judías estaban compuestas principalmente por los askenazíes y sefardíes, la población de Pirot pertenecía exclusivamente al llamado grupo sefardí (Lebl 2015: 25). 


\section{El establecimiento de los sefardíes en Pirot}

No se conoce el año de llegada de los judíos españoles a Pirot, asimismo el nombre de la ciudad no se menciona en la lista de lugares donde se establecieron los sefardíes. Sin embargo, en la importante ruta entre Sofía y Niš, esta nación no omitió Pirot, donde estableció una comunidad judía pequeña. A pesar de que no existe un gran número de documentos escritos sobre la población judía en esta ciudad, se sabe que en el siglo XVI ya existía una comunidad judía que tenía una sinagoga, tribunal rabínico, una escuela, un baño ritual y un cementerio (Lebl 2015: 44). Al mismo tiempo, aporta evidencias sobre la existencia de los sefardíes una descripción de la función de los comerciantes de Dubrovnik en la expansión de tiendas en los Balcanes, donde los judíos en el siglo XVII figuraban como importantes intermediarios comerciales entre B. Resti, el distribuidor de Dubrovnik, y la población local. Además, la lápida del rabino Shlom Gershon Kova de 1739, con una inscripción en hebreo indica que las familias sefardíes tenían residencia permanente en esta ciudad (Velkova \& Panajotović 2015: 10-12).

\subsection{La comunidad sefardí}

Al llegar a Pirot, los sefardíes se instalaron en la parte de Pazar. De acuerdo con el censo de 1879, en esa ciudad vivían 8.138 habitantes, de los cuales había 360 judíos (Nikolić 1981: 170). Después del decreto de Hati-Sherif en 1830, la población sefardí recibió el permiso de las autoridades turcas para construir una sinagoga $u$ otras instalaciones para un mejor funcionamiento de la comunidad judía. Por lo tanto, se construyeron escuelas, la comunidad judía y el baño ritual durante ese período (Radovanović \& Mihailović 2013: 101).

\subsubsection{La sinagoga}

La primera sinagoga de la comunidad judía en Pirot, llamada Kal (heb. Kahal - congregación) fue construida en el siglo XVI, aunque su ubicación se desconoce (Lebl 2015: 54). Hasta la liberación de los turcos en 1878, el rabino de la sinagoga mencionada fue Meir Konfino (Mejir Konfino) quien, después de la nueva situación, escapó de Pirot. Además de él, los rabinos conocidos en Pirot eran Avram Menashe, Ben Zion Menashe y Sabitaj Ruben. Al estabilizarse la situación en la ciudad, en 1890 los sefardíes obtuvieron la oportunidad de construir nuevos edificios, es decir, la sinagoga y la escuela de materiales más duros como el ladrillo. Un año 
más tarde el edificio de la sinagoga fue añadido al Plano Regulatorio de Pazar (Velkova \& Panajotović 2015: 32-33). Por otra parte, es conocido que el edificio de la Nueva Sinagoga (El Kal Nuevo), fue renovado en 1932, después del terremoto de Bulgaria en 1928, cuando, además de este edificio, fue dañada la Mezquita del Emperador en el centro de Pirot. Con la renovación de la sinagoga, se construyó un edificio donde había una gran sala y una galería, donde se reunían las mujeres y el coro.

Asimismo, es importante destacar que las mujeres sefardíes de ese período no tenían la igualdad con los hombres. Es decir, "las mujeres durante los servicios religiosos fueron separadas de los hombres y estaban sentadas en la galería que fue rodeada de barras para que pudieran observar lo que estaba sucediendo en el templo, mientras que nadie podía verlas" (Lebl 2015: 29). Teniendo en cuenta que la propiedad judía estaba bajo la administración de la Federación de Comunidades Judías de Yugoslavia en Belgrado, después del Holocausto cuando en Pirot ya no había más judíos, se decidió vender las sinagogas y otros edificios a la ciudad de Pirot. Después de sólo seis meses, el 5 de septiembre de 1958, fue tomada la decisión sobre la demolición del edificio de la sinagoga con la que termina la historia de este edificio monumental (Velkova \& Panajotović 2015: 36).

\subsubsection{El baño ritual (la mikve)}

Además de la construcción de la sinagoga, los judíos de Pirot poseían el otro edificio religioso, que les ofrecía la oportunidad de mejorar el funcionamiento de su propia comunidad y cuidar su identidad nacional. Uno de estos edificios fue el baño ritual, la mikve, cuyo significado fue mucho mayor que la construcción de la sinagoga y que tenía una gran importancia para la vida religiosa de las mujeres. Este baño ritual representaba un espacio lleno de agua pura, cuya función se reflejaba en el hecho de que la persona impura se limpia mediante el ritual de inmersión en agua limpia (Radovanović \& Mihailović 2013: 51).

El ritual de la mikve es uno de los más antiguos que tiene el pueblo judío. El agua está profundamente asociada no solo a la tradición judía, sino a una cantidad de culturas en todo lo que concierne a la purificación, la espiritualidad y el renacimiento. Inicialmente tiene que ver con la idea de la renovación (Tejero Yosovitch 2015: 3).

La construcción del baño ritual en Pirot tenía tres habitaciones, de las cuales solo una se ha conservado hasta hoy. El baño mencionado 
fue construido en Pirot en el período cuando se construyeron otros edificios alrededor de la sinagoga, es decir, en la primera mitad del siglo XX y les sirvió a los sefardíes hasta 1958, cuando fue demolido (Velkova \& Panajotović 2015: 40). Alentados por el trabajo y por el deseo de preservar la comunidad judía en esta ciudad, los judíos de Pirot en los primeros años de su llegada lograron construir instalaciones importantes y desarrollar la cooperación con la población local. Sin renunciar a su religión, se esforzaron durante mucho tiempo para sobrevivir y conservar las costumbres que formaban parte de su identidad.

\section{La vida religiosa de los sefardíes}

Mientras se acostumbraban al nuevo entorno, los sefardíes estaban tratando al mismo tiempo de respetar sus costumbres, vida religiosa, fiestas importantes y tradiciones, que eran muy importantes para preservar su identidad social y, por tanto, ralentizar la asimilación y la integración con la población étnica serbia. En consecuencia, "los devotos sefardíes pasaban mucho tiempo leyendo los libros religiosos en la Yeshiva, al mismo tiempo escuchando las historias orales" (Daniti 1939: 9).

Los rituales religiosos y otros aspectos de la vida de los sefardíes se llevaron a cabo principalmente conforme a las disposiciones de carácter religioso y social que eran el producto de muchas generaciones de eruditos judíos (Urbach 1927: 71 apud Vučina Simović \& Filipović 2009: 77). Acostumbrados a la lucha de la vida diaria y la confrontación con la dura realidad, la población sefardí se las arregló para soportar todos los obstáculos y mantener sus tradiciones culturales. Por consiguiente, las generaciones jóvenes fueron educadas en el espíritu tradicional, respetando sus festividades y costumbres. Entre las fiestas judías más importantes estaba la Pascua, Shavuot, Rosh Hashaná (Año Nuevo Judío) y Yom Kipur (Jevtić 2011: 212).

Muchas fiestas judías se respetaban, lo que demuestran los numerosos casos de liberación de obligaciones de los estudiantes y soldados de Pirot. En los fondos de la comunidad judía (CJ) del Archivo Histórico de Niš (1996) se pueden encontrar ejemplos de la solicitud del 24 de marzo de 1910 de la administración del municipio judío enviada al comandante del XVI Regimiento de Infantería para pedir la exención para los soldados durante la Pascua (CJ-51); la solicitud del 25 de mayo de 1910 también al comandante del decimosexto regimiento para eximir a los soldados del servicio militar durante la fiesta de Shavuot (CJ-73); la solicitud del 17 de septiembre de 1910 donde se pide la exención para los soldados durante 
las vacaciones de Rosh Hashaná y Yom Kipur (CJ-136), así como para los estudiantes de escuela primaria y Liceo de Pirot (CJ-140).

\section{Las profesiones de los miembros de la comunidad judía}

Motivados por el objetivo de bienestar de su comunidad, los judíos españoles en esta ciudad del sur, asimismo, dejaron huella en los negocios de la ciudad. En concreto, un gran número de judíos de Pirot trabajaron en la artesanía y el comercio. Eran famosos por la importación de algodón y textiles y la exportación de los productos lácteos, cereales y pieles. Teniendo en cuenta su formación tradicional, los sefardíes respetaban y mantenían sus costumbres, celebraban las fiestas importantes y los sábados no abrían sus tiendas y talleres.

Sin embargo, pocos años después de la liberación de los turcos, se tomó la decisión sobre la introducción de un día de mercado durante el reposo, lo que llevó al hecho de que judíos de Pirot se sintieran amenazados y mal entendidos por la población serbia. A pesar de haber solicitado a las autoridades el cambio del día de mercado, a fin de no violar las leyes de su religión, no hubo ningún cambio de la situación, por lo que se vieron obligados a abrir sus talleres y tiendas con el fin de mantener a sus grandes familias (Lebl 2015: 67-68).

Igualmente, la autora Jennie Lebel (2015: 68) destaca que entre las filas de las organizaciones judías de Pirot había muchos ingenieros, médicos, farmacéuticos, veterinarios, fotógrafos, pilotos, jugadores de fútbol y actores de teatro. También eran conocidos dos oficiales activos del Ejército Real de Yugoslavia, los coroneles Avram Beraha y Aleksandar Aronović. En cuanto a las mujeres sefardíes, Rena Abravanel era conocida como miembro de la tercera comisión del Partido Comunista de Yugoslavia en Belgrado. En 1941 Rena se unió al batallón de partisanos de Durmitor en Montenegro junto con su esposo, pero en junio de 1942 fue capturada y herida cuando los chetniks la entregaron a los italianos, que la dispararon en Kolašin en el año 1943. Consecuentemente, el heroísmo de esta mujer se destaca en las canciones de Montenegro.

\section{La vida de los judíos de Pirot desde mediados del siglo XIX hasta el final de la Primera Guerra Mundial}

Durante el gobierno de los turcos, los judíos de Pirot a mediados del siglo XIX tuvieron la oportunidad de ser parte de las autoridades con facultades limitadas. A saber, la población judía podría tener un 
representante en la asamblea cuyo papel era el control de los recortes de impuestos. En 1872 los turcos permitieron a esta nación tener jurisdicción sobre la decoración de la ciudad. En este período, mientras se pagara debidamente el impuesto al gobierno turco, la población sefardí podría poseer tierras, es decir, viñedos, campos y prados (Nikolić 1974: 68-69).

La región de Pirot fue liberada el 28 de diciembre de 1877 de las autoridades turcas. Después de la liberación el ejército serbio fue bienvenido ceremoniosamente, pero la presencia de los judíos no se menciona.

En el nuevo gobierno de la ciudad en 1878, dos miembros de la comunidad sefardí obtuvieron posiciones de concejales, mientras que el año siguiente el número de representantes de la comunidad judía aumentó y entre ellos destacaron: Haji Mair, Bor (Bohor) Konfino, Haji Salomon, Azriel David, Hamachi Naftali y Mosha Beraha (Nikolić 1981: 209, 294, 344).

\section{1. La guerra serbo-búlgara, las guerras de los Balcanes y la Primera Guerra Mundial}

Después de la liberación de los turcos, empezó un período tranquilo para esta población, que duró hasta el comienzo de la guerra serbo-búlgara de 1885-1886, cuando la ciudad de Pirot en noviembre y diciembre de 1885 estaba bajo la ocupación búlgara. En el período de un mes, la maale judía fue atacada por el ejército búlgaro que destruyó la sinagoga (Nikolić 1981: 165-167). Por consiguiente, teniendo en cuenta que judíos y serbios eran amigos, los búlgaros atacaron rápidamente a los judíos y empezaron a robar sus posesiones y a destruir sus casas. Esto hizo que setenta familias, de las entonces ochenta, se quedaran sin recursos necesarias para la vida y tuvieran que huir a Niš (Actas de la Federación de Comunidades Judías. 4: 283 apud Lebl 2015: 46).

Sin embargo, con el tiempo hubo una nueva guerra y después de un periodo tranquilo en Serbia, la participación de los judíos en las guerras continuó. A saber, desde la guerra entre Serbia y Turquía, los judíos obtuvieron el derecho de rango, por lo que su posición en la sociedad y el ejército mejoró. Ellos comenzaron a tomar parte en todas las guerras con los serbios y muchos de ellos fueron premiados con medallas por sus méritos, sobre todo en las guerras de los Balcanes y la Primera Guerra Mundial (Jovanović 1992: 131-132; Lebl 2001: 191-196 apud Vučina Simović \& Filipović 2009: 108).

De la misma forma, como otros judíos en Serbia, los sefardíes de Pirot ayudaron a la población serbia local generosamente y, además, 
participaron en las guerras, primero en las guerras de los Balcanes de 1912 a 1913 y luego en la Primera Guerra Mundial de 1914 a 1918. Según los datos de 1913, 35 judíos de Pirot se alistaron en las filas del ejército serbio, es decir, el 14\% de los judíos en esa ciudad (Lebl 2015: 49). En las guerras hubo muchas víctimas de origen judío de Pirot entre las cuales se conocen los siguientes nombres: Majer Bencion Konfino, Solomón Ruben Frako, Jakov M. Saltiel, Haim Josif Dzivan, Mosha Levi Naftali, David B. Samuel (Davidović) (La edición del comité para erigir monumentos a los guerreros judíos asesinados 1927: 20-120 apud Velkova \& Panajotović 2015: 25).

En el año 1915, después de la retirada del ejército serbio, los búlgaros entraron de nuevo en Pirot y llevaron a los judíos de las familias más ricas a campos de trabajo forzado en Bulgaria. Aquel periodo lleno de destrucción de edificios judíos duró hasta 1918, cuando en octubre las autoridades de ocupación de Bulgaria dejaron la ciudad de Pirot y la población, poco a poco, volvió a su rutina diaria en la que la relación y la cooperación entre los serbios y los judíos sefardíes eran más fuertes.

\section{Los sefaradíes de Pirot entre las dos guerras mundiales}

A pesar de que la comunidad judía de Pirot tenía menos miembros, en comparación con Belgrado y Niš, los sefardíes de este pequeño lugar también tenían grandes objetivos en cuanto a una educación de calidad para su juventud y, al mismo tiempo también les ofrecían actividades culturales y deportivas, a pesar de poseer modestos recursos económicos.

\subsection{La educación de la juventud sefardí}

La escuela judía (Meldar) en Pirot estaba ubicada en el patio de la sinagoga (Kal), en el edificio del municipio judío. "El maestro enseñó a los niños en el judezmo (judeoespañol o ladino)" (Lebl 2015: 64). Es conocido que los niños de 5 a 12 años iban a la escuela, que duraba 7 años. Al igual que en todas las escuelas judías de Serbia, las clases se impartían en hebreo y los estudiantes aprendían lectura, escritura, como contar y religión. Después de la liberación de las autoridades turcas, se observó que en dicha escuela había 18 alumnos matriculados en el primer grado, mientras que en el segundo había 12 alumnos (Dimitrijević 1968: 190 apud Velkova \& Panajotović 2015: 47). Hasta principios de junio de 1892, el maestro era Nisim Varona y en ese período había 55 alumnos en la escuela judía (Nikolić 1981: 832). 
Los sábados El Meldar estaba cerrado, pero los domingos desde las 7 hasta 10 de la mañana los estudiantes de las escuelas primarias y de la escuela secundaria iban a las clases de religión obligatorias. Hasta el año 1934, a los estudiantes judíos de la escuela primaria les enseñaba la religión judía Chelebon Tuvi Bahar Josef, mientras que los estudiantes de la escuela secundaria aprendían esta materia de Nisim Jakov Adijes. Es interesante que enfrente de la sinagoga estaba el pequeño Midrash, una especie de seminario, donde los judíos españoles tenían la costumbre de venir durante la semana, y los sábados por la mañana en el mismo lugar los mayores de origen judío estudiaban el archivo cabalístico Zohar (El libro de esplendor) (Lebl 2015: 64).

A finales de los años 80 del siglo XIX comenzó la adaptación gradual de los jóvenes sefardíes al sistema escolar de Serbia. En primer lugar, ellos empezaron a ir a la escuela y continuaron su educación en el Liceo de Pirot, mientras que la matriculación en la escuela primaria de Serbia se trasladó a principios del siglo XX. Desde entonces comenzó la integración de los jóvenes judíos de Pirot en el sistema escolar de Serbia, que probablemente influyó en su rápida adaptación a nuevos modelos culturales y al lenguaje de la comunidad serbia.

Se concluye que la educación y las escuelas de ese tiempo eran un ejemplo destacado de la política de enseñanza de idiomas, mientras que en otras comunidades minoritarias, comenzó a ponerse en práctica la adquisición de la lengua mayoritaria es decir, el serbio.

El momento en que los miembros de una comunidad lingüística en particular ya no perciben su lenguaje como útil, es decir, cuando el idioma de la mayoría educativo, económico, político se convierte en valioso recurso para la supervivencia y la mejora de la situación socioeconómica y el prestigio ganando dentro de la comunidad en general, el proceso de sustitución de la lengua comienza, inevitablemente y la lengua minoritaria se mantiene a nivel del valor sentimental de la lengua étnica (Vučina Simović \& Filipović 2009: 166).

El primer graduado judío de la escuela secundaria de Pirot fue Avram Beraha en 1897/98. En los siguientes años escolares, el número de estudiantes de origen sefardí creció. Entre ellos se destacaron: Moshon Beraha, Moshon Aronović, Haim Sid, León Levi, León Sid, Jusuf Isaković. Algunos de los judíos continuaron con su educación y terminaron estudios universitarios de medicina, veterinaria, derecho, farmacia, agronomía, tecnología. Por ejemplo, Mosha Levi se graduó en la Facultad 
de Derecho, Marko Haim Avramović terminó los estudios de odontología, mientras que Samuel León Avramović fue ingeniero químico (Velkova \& Panajotović 2015: 49-50).

\subsection{El derecho de las mujeres sefardíes a la educación}

Desde la expulsión, la parte femenina de la población sefardí tuvo muchas limitaciones en sus elecciones. Hasta la segunda mitad del siglo XX, las mujeres no podían ser educadas fuera del hogar. Principalmente, su educación estuvo basada en el aprendizaje de las letras y la lectura, y después se estaban preparando para convertirse en futuras amas de casa a cargo exclusivamente de su familia (Díaz Mas \& Sánchez Pérez 2010: 19-20).

En los Balcanes, las mujeres sefardíes durante siglos marcaron el pilar de la identidad nacional y lingüística de la comunidad sefardí, y por lo tanto tenían un impacto importante en el uso del lenguaje en la familia. Dirigidas a la familia y el hogar, las mujeres continuamente estaban transmitiendo a su descendencia la lengua y las tradiciones orales y costumbres (Vučina Simović \& Filipović 2009: 54, 148). El aislamiento inevitable de las mujeres en la sociedad sefardí hizo posible poder preservar mejor sus raíces, la religión, las costumbres tradicionales, mientras que los hombres tenían el papel principal en el funcionamiento de la política, la economía y enfatizaron el poder social (Filipović \& Vučina Simović 2010: 262).

Por otro lado, las mujeres sefardíes en el mundo patriarcal, sin duda, representaban una minoría que no tenía poder social y económico, tanto en sus comunidades étnicas como en otros entornos sociales. Por lo tanto, se puede destacar que esas mujeres fueron un grupo inferior de la sociedad, a menudo discriminadas y excluidas en la creación de la realidad social en aquel período histórico (Filipović 2009 apud Filipović \& Vučina Simović 2010: 262).

Los derechos y oportunidades de tomar decisiones para la comunidad obviamente estaban limitados para las mujeres de origen sefardí. Sin mezclarse con otros ciudadanos de otras naciones y religiones, las mujeres pasaban los días en el hogar haciendo las tareas de la casa y cuidando de la familia lo que causó que preservaran más su lengua y costumbres. Sin embargo, con el tiempo, empezó a cambiar el estado de esas mujeres y ellas comenzaron a dar los primeros pasos hacia su educación y emancipación. Finalmente, se permitió que las niñas judías se educaran en las escuelas al igual que los niños. 
Por ejemplo, en el caso de la ciudad de Pirot, existe una evidencia de que la escuela primaria femenina privada de Pirot la terminó Lika Beraha 1907/8 donde también aprobó el examen de lengua alemana (Nikolić 1981: 805). Igualmente, algunas mujeres sefardíes aprendían a hacer manualidades y otras se convirtieron en famosas sastras, como Vinka Jusef Avramović, Stela Mosha Alkalaj, Berta Pesah Levi (Velkova \& Panajotović 2015: 49).

\subsection{Las actividades deportivas e influencia sefardí en la población local}

Esforzándose para desarrollar su comunidad en Pirot, los sefardíes participaron activamente en las actividades educativas, culturales y deportivas. Además, las autoras Velkova y Panajotović (2015: 51) destacan el dato que los judíos después de la Segunda Guerra Mundial participaron activamente en la vida cultural de Pirot y señalan que tenían su propio coro que participaba a menudo en la sinagoga y otras festividades, la orquesta de tamborín desde 1921 hasta 1923 y se dedicaban a la actuación en el teatro.

En cuanto a la vida deportiva de la ciudad, los judíos de Pirot eran miembros del comité de dirección, participaron en la Asamblea Constituyente y eran jugadores de fútbol y árbitros de fútbol de clubes. Como una de las personalidades de la vida deportiva de Pirot destacó Mosha Josef Dživan, fundador del Club de fútbol juvenil de Pirot en 1920, donde fue jugador y miembro de la junta hasta 1925 cuando murió trágicamente en el partido en Skopje (Živković 2004: 125). Asimismo, en la vida deportiva de Pirot destacaron muchos jugadores y trabajadores de deporte de origen sefardí como Mosha Israel Levi, Efraim Mosha Levy, Razina Sid, Rashela Castro y otros, mientras que los mayores se acuerdan bien de Avram Samuel Avramović, el árbitro de fútbol, que después de la Segunda Guerra Mundial, en 1944 volvió a Pirot (Velkova \& Panajotović 2015: 51-52).

Por otra parte, aparte de los éxitos deportivos y otras actividades culturales y educativas, los judíos de origen español también provocaban una cierta curiosidad de población local de Pirot también por su estilo de vida habitual. Cuando los sefardíes llegaron a Pirot, introdujeron gradualmente nuevas costumbres en este entorno, que fueron adoptadas por algunos de sus vecinos. Por ejemplo, los judíos de Pirot comenzaron a pintar sus casas. Poco después, la mayoría de los ciudadanos aceptaron esta "moda" y comenzaron a trabajar en sus casas (Nikolić 1974: 31).

También, es interesante que la población local se encontrara con otra novedad. Los judíos ricos de Constantinopla, los hermanos Jakov y 
Nisim Papo, que tenían relaciones comerciales con Pirot y comerciantes serbios y judíos, tenían un taller de elaboración de quesos. Además de la producción de queso, su trabajo era mostrar a la gente local cómo se elabora el queso (kačkavalj), que en ese momento era un evento especial al que asistió la mayoría de los ciudadanos (Lebl 2015: 43). Para concluir,

el desarrollo de las comunidades judías entre la Primera y Segunda Guerra Mundial representa un periodo especial en la historia de los judíos de estas áreas que marcará para siempre la dirección del desarrollo de una participación mayoritaria de la comunidad y después del Holocausto. Las comunidades judías, asociaciones y organizaciones que habían florecido en este periodo y tenían la gran influencia en la sociedad yugoslava hoy en día son una característica importante de la vida judía en esta región (Viličić et al. 2014: 20).

\section{El sufrimiento de los judíos de Pirot en la Segunda Guerra Mundial}

Después de la Primera Guerra Mundial, la adaptación de los miembros de la comunidad sefardí en Pirot a la población local y viceversa fue cada vez más evidente, donde las relaciones interpersonales mejoraron y duraron así bastante tiempo. Esto se evidencia en la siguiente declaración:

En la ciudad de Pirot fueron muchos serbios que trabajaban con los judíos, se llevaban muy bien y respetaban como parientes de sangre. Entonces, muchos serbios aprendieron el idioma judío y hablaron con tanta prudencia que nadie podía sospechar que no eran judíos por nacionalidad (Nikolić 1974: 46).

Sin embargo, el ambiente equilibrado y estable creado entre la población judía y serbia de Pirot fue interrumpido por la Segunda Guerra Mundial, un evento implacable que interrumpió la vida de muchos judíos en Serbia. El exterminio masivo de los judíos se estaba acercando y también afectó a los sefardíes de Pirot, que nuevamente estuvieron bajo la ocupación búlgara en 1942. Teniendo en cuenta que la comunidad judía de Pirot perdió rápidamente su independencia bajo el gobierno búlgaro, Bulgaria formó un nuevo órgano - el consistorio. El consistorio judío tenía cinco miembros que fueron: Israel Moshe Levi, León Mordejai Sid, Moshe Nisim Abravanel, Mair Jako Levi, Samuel Avram Avramović (Velkova \& Panajotović 2015: 91).

Por desgracia, de todas partes llegaron noticias de las víctimas judías de Niš y Belgrado bajo el gobierno alemán, por lo que los sefardíes 
de Pirot eran más conscientes de lo que les esperaba a todos. Muy pronto empezaron diferentes tipos de prohibiciones y acoso y que finalmente tuvo lugar la detención de la mayoría de los sefardíes en Pirot el 12 de marzo en 1943. Aquellos que estaban capturados en el campo de Sokolana, experimentaron una tortura implacable hasta el 19 de marzo de aquel año, cuando varios presos judíos de Pirot fueron deportados en tren a Polonia, al campo de exterminio - Treblinka, donde fueron asesinados (Lebl 2015: 98). Como se registra, después de la Segunda Guerra Mundial sólo volvieron Samuil Avram Avramović e Isak Tuvi Josefović que vivieron hasta 1950 en Pirot cuando la ciudad se quedó sin familias judías que durante muchos años hicieron una contribución generosa a la región de Pirot.

\section{Conclusiones}

La migración de la población sefardí después de la expulsión de 1492 hizo que los sefardíes se mudaran a otros países y se adaptaran a nuevos entornos, lo que trajo consigo muchos desafíos. Guiados por el deseo de encontrar nuevos refugios, los sefardíes se establecieron en la ciudad de Pirot. Con un menor número de miembros, los judíos españoles construyeron en Pirot la sinagoga, el baño ritual - mikve, manteniendo y reforzando la vida religiosa y celebrando las fiestas importantes. Además de fortalecer la tradición, los judíos de Pirot trabajaron duro y participaron activamente en los asuntos de la ciudad, y en su mayoría destacaron en el comercio y la artesanía.

Después de las autoridades turcas, Pirot a menudo fue atacado por los ocupadores búlgaros, lo que causó numerosos inconvenientes y adversidades para los sefardíes. No obstante, con ganas de luchar contra los invasores y también ayudar a los vecinos y autoridades de Serbia, los judíos de Pirot tomaron parte en las guerras de los Balcanes y la Primera Guerra Mundial. A pesar de las dificultades de la vida diaria, los sefardíes en todo momento invirtieron en la educación de su juventud y otros miembros de la comunidad realizando muchas actividades culturales y deportivas. Aunque la gran intención era preservar su identidad étnica, la asimilación a la población serbia era inevitable desde que la juventud judía entró en el sistema educativo serbio, lo que contribuyó a la pérdida de su lengua ladino, que se mantuvo exclusivamente dentro de la familia.

Finalmente, la mayoría de los habitantes de Pirot aceptaron a los judíos. Las relaciones interpersonales habían mejorado y la vida se había normalizado hasta la Segunda Guerra Mundial, cuando muchos judíos, incluidos lo miembros de la comunidad de Pirot, perdieron la vida. En un 
breve periodo de tiempo, numerosas familias fueron destruidas, y todo lo que habían creado sufrió el mismo destino. Este evento trágico hizo que hoy en día no quedaran miembros de la comunidad judía en Pirot, y que las últimas huellas de su existencia anterior se perdieran y desaparecieran casi por completo.

\section{BIBLIOGRAFÍA}

Baho Alvares, Fe \& Hulio Hil Pećaroman. Istorija Španije. Prevela Biljana Bukvić. Beograd: Clio, 2003. Štampano.

Daniti, Avram. „O niškoj jevrejskoj zajednici“, Vesnik, br. 5, 9 (1939): S. P. Web. 15 Ene. 2019.

Díaz Más, Paloma \& María Sánchez Pérez. "Los sefardíes ante los retos del mundo contemporáneo. Identidad y mentalidades”. Paloma Díaz Más \& María Sánchez Pérez (Eds.). Los sefardíes ante los retos del mundo contemporáneo. Identidad y mentalidades, Madrid: CSIC, 2010: 11-29. Impreso.

Filipović, Jelena \& Ivana Vučina Simović. "La lengua como recurso social:

El caso de las mujeres sefardíes de los Balcanes". Paloma Díaz Más \& María Sánchez Pérez (Eds.). Los sefardíes ante los retos del mundo contemporáneo. Identidad y mentalidades, Madrid: CSIC, 2010: 259-269. Impreso.

Jevtić, Dragica (Ur.). Niški leksikon. Beograd: Službeni glasnik i grad Niš, Edicija Leksikon gradova Srbije. 2011. Štampano.

Lebl, Ženi. Jevreji u Pirotu, drugo dopunjeno izdanje. Pirot: Muzej Ponišavlja Pirot, 2015. Štampano.

Nikolić, Ilija. Pirotska Gimnazija 1879-1979. Pirot: Gimnazija „Predrag Kostić", 1979. Štampano.

Nikolić, Ilija. Pirot i srez nišavski 1801-1918. Pirot: Muzej Ponišavlja Pirot, 1981. Štampano.

Nikolić, Vladimir. Stari Pirot, Etnološke beleške iz prošlosti grada. Pirot: Muzej Ponišavlja Pirot, 1974. Štampano.

Radovanović, Vojislava \& Milica Mihailović. Životni ciklus - običaji kod Jevreja, reprint prvog izdanja iz 1998. Beograd: Savez jevrejskih opština Srbije, Jevrejski istorijski muzej, 2013. Štampano.

Soldatić, Dalibor \& Željko Donić. Svet hispanistike, Uvod u studije. Beograd: Zavod za udžbenike, 2011. Štampano.

Stanojević, Stanoje. Narodna enciklopedija srpsko-hrvatsko-slovenačka. Zagreb: Bibliografski zavod, 1926. Štampano. 
Tejero Yosovitch, Yael. "El agua de arriba y el agua de abajo. El baño ritual en la tradición judía”. Andén, 81 (2015): S. P. Web. 20 Ene. 2019.

Velkova, Saška \& Mila Panajotović. Šalom iz Pirota. Pirot: Muzej Ponišavlja Pirot, 2015. Štampano.

Viličić, Sonja et al. Portreti i sećanja jevrejske zajednice Srbije pre Holokausta: Priručnik za nastavnike i nastavnice. Beograd: Savez jevrejskih opština Srbije, 2014. Štampano.

Vodič kroz arhivsku građu Srbije. Vodič istorijskog arhiva Niš. Fond Crkveno-školska jevrejska opština JOP Niš 1695-1941. Niš: Istorijski arhiv Niš, 1996. Štampano.

Vučina Simović, Ivana \& Jelena Filipović. Etnički identitet i zamena jezika u sefardskoj zajednici u Beogradu. Beograd: Zavod za udžbenike, 2009. Štampano.

Živković, Hristifor. 80 godina fudbala u Pirotu i okolini 1920-2000. Pirot: Muzej Ponišavlja, 2004. Štampano.

\section{THE SEPHARDIC JEWISH COMMUNITY IN PIROT}

\section{Summary}

When the Sephardic population was expelled from Spain in 1492 and Portugal in 1496, the life of this ethnic and religious group had been completely changed and adapted to new environments. Looking for refuge in other countries, during the Turkish domination, the Sephardic Jews came to city of Pirot. In this city in the southeast, Spanish Jews established the Jewish community and began a new life with the local population. They built a synagogue, the ritual bath - mikve, they kept the traditions and religious festivals, but at the same time they were successfully engaged in trade work. Despite the lack of material resources, the Sephardic Jews in Pirot invested in the education of young people and other cultural and sports activities. However, many wars, starting with the Serbo-Bulgarian war through the Balkan Wars, the First World War until the Second World War, caused the unpleasant situations and the disappearance of the Sephardic community of Pirot after the Holocaust, when many Jews were brutally tortured and killed in this horrible event.

Keywords: Sephardic Jews, Pirot, Jewish community, ethnic identity. 